\title{
Role of RTPCR in Early Dengue Diagnosis: A Latest Update
}

\author{
Rami Abdullah Ali-Al Dagrer ${ }^{1 *}$, Ali Mohammed Qushaish ${ }^{2}$, Smita Sharma ${ }^{3}$, Ramesh Maheshwari ${ }^{4}$ \\ ${ }^{1}$ Master in Biotechnology, Director Blood Banks and Laboratories, Nejran zone KSA \\ ${ }^{2}$ Master in Clinical Science, General Directorate of Laboratories and Blood Banks, Ministry of Health KSA \\ ${ }^{3}$ MD, DTCD, Clinical Biochemist, Regional Lab Nejran KSA \\ ${ }^{4}$ MD Medicine, Distt.Health Officer, Punjab Public Service Commissin, Bhatinda India
}

\author{
DOI: $10.36348 /$ sjm.2019.v04i11.002 $\quad$ | Received: 04.11.2019| Accepted: $11.11 .2019 \mid$ Published: 18.11 .2019 \\ *Corresponding author: Rami Abdullah Ali-Al Dagrer
}

\section{Abstract}

Dengue fever is one of the most common arthropod-borne viral infectious diseases. The disease is now endemic in more than 100 countries in Africa, the Americas, the Eastern Mediterranean, Southeast Asia and the Western Pacific with an estimated two fifths of the world's population being at risk. The notable endemic viral hemorrhagic fevers (VHFs) found in West Africa, including yellow fever, Lassa fever, Rift Valley fever, dengue fever and until recently Ebola have been responsible for most outbreaks with fatal consequences. These VHFs usually produce unclear acute febrile illness, especially in the acute phase of infection. In this context, early detection of infection with sensitive and specific laboratory tools and the prompt clinical management of this disease is a health care priority. Rapid and accurate methods for the diagnosis of dengue fever are important for optimum patient management and institution of early preventive strategies. In this review we tried to focus on role of Molecular methods in early and definitive diagnosis of dengue.

Keywords: Dengue, Viral hemorrhagic fever, Molecular method.

Copyright @ 2019: This is an open-access article distributed under the terms of the Creative Commons Attribution license which permits unrestricted use, distribution, and reproduction in any medium for non-commercial use (NonCommercial, or CC-BY-NC) provided the original author and source are credited.

\section{INTRODUCTION}

Dengue is vector-borne infectious disease. Dengue virus (DENV), a member of the family Flaviviridae, genus Flavivirus, consists of four serologically related but antigenically distinct serotypes designated DENV-1, 2, 3, and 4 [1]. These viruses are transmitted to humans primarily by Aedes aegypti and Aedes albopictus mosquitoes [2]. Infection with DENV generally causes a mild, febrile illness or classic dengue fever that can progress to the severe disease forms, dengue hemorrhagic fever (DHF) and dengue shock syndrome (DSS), which can be fatal [3, 4]. Considering the broad spectrum of clinical presentations of dengue, as well as the differential diagnosis to other diseases, laboratory confirmation is essential.

CDC recommends that dengue virus testing should be done to anyone who travelled to area where dengue is endemic and experienced symptoms like fever, headache, rash, bodyaches and bleeding manifestations. Symptomatic pregnant women with possible dengue or Zika virus exposure. Dengue virus testing is not recommended for: asymptomatic patients and Preconception screening. Diagnostic tests for dengue are Molecular tests, Dengue virus antigen detection (NS1), Serological tests and Tissue tests.
Patients with symptoms consistent with dengue can be tested with both molecular and serologic diagnostic tests during the first 7 days of illness. After the first 7 days of illness, test only with serologic diagnostic tests [5].

Fever is the most common presenting symptom and often coincides with viremia [6] and nonstructural protein 1 (NS1) antigenemia[7, 8]. NS1 is a soluble protein, and it has been shown to be present in serum for up to nine days after onset of fever in a proportion of DENV-1 infected patients [9] and is therefore the target for several diagnostic tests. Ever since these assays were introduced, they have been widely used for early dengue diagnosis [10-12]. Unfortunately, recent evaluations have shown that although the NS1 antigen detection tests offer high specificity [13, 14], they differ markedly in sensitivity [13, 15-17].

Serological diagnosis is usually achieved by detecting DENV-specific IgM and IgG antibodies, which start to appear during the early post-febrile period [18]. A primary infection is characterized by slow and low-titer antibody responses, and $\operatorname{IgM}$ antibodies represent the dominant isotype. IgM antibodies appear by day 2 to 5 of illness [19, 20], 
whereas IgG antibodies generally become detectable at the end of the first week after onset of symptoms. The opposite is typically observed in secondary infections: IgM antibody levels are undetectable or low, and IgG antibody titers rise rapidly [19]. Consequently, laboratory diagnosis based entirely on detection of $\operatorname{IgM}$ antibodies can give false-negative results in patients that have previously been infected with DENV [19]. Unspecific reactions are also an important issue to consider in dengue serodiagnosis. Commercially available tests for rapid detection of $\operatorname{IgM}$ antibodies have been shown to produce false-positive results in sera positive for anti-DENV IgG, malaria, and rheumatoid factor [21], and assays detecting antiDENV IgG antibodies can be vulnerable to crossreactions caused by antibodies against related viruses. .

\section{RT-PCR}

Due to the mentioned limitations of the conventional assays, the use of molecular methods to detect viral genomes for early diagnosis of dengue has increased. Molecular methods such as RT-PCR and nucleic acid hybridization have been used to great effect in successfully diagnosing DENV infection. PCR-based methods provide same- or next-day diagnosis of DENV during the acute phase of disease. Lanciotti et al. [22] originally reported a 2-step heminested RT-PCR assay that was highly sensitive. This method was then modified to a single-step multiplex real-time RT-PCR assay, which was adopted worldwide. A major advantage of PCR-based techniques is that viral RNA can be detected from the onset of illness and is sensitive, specific, fast, less complicated, and cheaper than virus isolation methods [23]. Single-step multiplex real-time RT-PCR assay, require advanced thermal cyclers that detect the four specific fluorophores for which these systems have been validated [24, 25]. The common denominator for most of these assays is the large number of primers and/or probes that are needed to detect the genomes of the four DENV serotypes [26, 24, 27, 25], which may complicate modifications of primer and probe sequences when new genetic variants of DENV emerge. RT-PCR has become a primary tool for the detection of viral RNA in acute phase of illness with sensitivity ranging from $80-90 \%$ and specificity of more than $95 \%$. A positive PCR result usually confirms the infecting serotype and provides a definite proof of current infection. However, a negative PCR result before 5 days of illness is interpreted as "indeterminate" and such patients are usually asked for serological confirmation by submitting second serum sample after 5th day of illness [28].

\section{Diagnostic Role of RTPCR in Fatal Cases}

Diagnosis of DENV infection in fatal cases often can be challenging because of the unavailability of serum and fresh or frozen specimens. Furthermore, in patients who die during the first week of illness, serology may have limited use because of low levels of
IgM antibodies that cannot be detected by serological assays [29]. On the other hand, in the early viremic stage of DENV infections patients may have higher viral loads [30-32]. Therefore, RT-PCR analysis of FFPE tissues, often the only specimens available for fatal cases, can be a useful adjunct to conventional diagnostic techniques, particularly in patients who die relatively soon after the disease onset. However, the application of RT-PCR for the detection of DENV in FFPE tissues has been very limited because of difficulties in extracting good quality RNA.

\section{Comparison of RTPCR with other Diagnostic assays in Dengue Diagnosis}

Carlos Palomares-Reyes et al. identified DENV in up to $25.74 \%$ of patients with an AFI via the detection of DENV RNA by RT-PCR. In addition, a correlation was established between the frequency of positive results and the serological tests that determine NS1, IgM, and IgG. It was found that there was a greater correlation between RT-PCR and NS1 ELISA for the diagnosis of acute DENV infection. There was growing need for confirmatory diagnostic laboratory tests for clinically defined dengue cases to strengthen epidemiological surveillance in endemic areas.Finally, it is concluded that the diagnostic accuracy of the tests investigated can be ordered from highest to lowest as follows: RT-PCR > NS1 ELISA > IgM ELISA[33].

JC Guzman et al. showed in phillipins that Thrombocytopenia, leukopenia, and hemoconcentration had specificities of $20 \%, 76 \%$, and $63 \%$ respectively, while sensitivities were found to be, $100 \%, 33 \%$ and $66 \%$, respectively. In contrast the molecular techniques mentioned had specificities that ranged from $82.7-100 \%$ and sensitivities of $69.2-99.6 \%$ [34].

\section{CONCLUSION}

Rising mortality and morbidity rates caused by infection in recent years are attributable partly to a lack of availability of effective antiviral therapies and vaccines.RT PCR has role in early diagnosis during viraemic stage as compare to other methods. Early diagnosis will helpful in proper patient management.

\section{REFERENCES}

1. Gubler, D.J. (1998). Dengue and dengue hemorrhagic fever. Clin Microbiol Rev, 11:480 496.

2. Gubler, D.J. (1988). In: The Arboviruses: Epidemiology and Ecology. Monath TP, editor. Volume 2. Boca Raton, FL: CRC Press, 223-260.

3. Centers for Disease Control and Prevention Dengue Clinical

Guidance. (2010). http://www.cdc.gov/dengue/clini calLab/clinical.html.

4. Halstead, S.B. (1988). Pathogenesis of dengue: challenges to molecular biology. Science, 239:476481. 
5. https://www.cdc.gov/dengue/healthcare providers/testing/index.html?CDC_AA_refVal=htt ps $\% 3 \mathrm{~A} \% 2 \mathrm{~F} \% 2 \mathrm{Fwww} . c d c . g o v \% 2 \mathrm{Fdengue} \% 2 \mathrm{Fclini}$ callab- \%2Flaboratory.html.

6. Gubler, D.J., Suharyono, W., Tan, R., Abidin, M., Sie, A. (1981). Viraemia in patients with naturally acquired dengue infection. Bull World Health Organ, 59: 623-630.

7. Moi, M. L., Omatsu, T., Tajima, S., Lim, C. K., Kotaki, A., Ikeda, M., \& Takasaki, T. (2013). Detection of dengue virus nonstructural protein 1 (NS1) by using ELISA as a useful laboratory diagnostic method for dengue virus infection of international travelers. Journal of travel medicine, 20(3), 185-193.

8. Tricou, V., Vu, H. T., Quynh, N. V., Nguyen, C. V., Tran, H. T., Farrar, J., ... \& Simmons, C. P. (2010). Comparison of two dengue NS1 rapid tests for sensitivity, specificity and relationship to viraemia and antibody responses. BMC infectious diseases, 10(1), 142.

9. Alcon, S., Talarmin, A., Debruyne, M., Falconar, A., Deubel, V., \& Flamand, M. (2002). Enzymelinked immunosorbent assay specific to Dengue virus type 1 nonstructural protein NS1 reveals circulation of the antigen in the blood during the acute phase of disease in patients experiencing primary or secondary infections. Journal of clinical microbiology, 40(2), 376-381.

10. Fry, S. R., Meyer, M., Semple, M. G., Simmons, C. P., Sekaran, S. D., Huang, J. X., ... \& Cooper, M. A. (2011). The diagnostic sensitivity of dengue rapid test assays is significantly enhanced by using a combined antigen and antibody testing approach. PLoS neglected tropical diseases, 5(6), e1199.

11. Chaiyaratana, W., Chuansumrit, A., Pongthanapisith, V., Tangnararatchakit, K., Lertwongrath, S., \& Yoksan, S. (2009). Evaluation of dengue nonstructural protein 1 antigen strip for the rapid diagnosis of patients with dengue infection. Diagnostic microbiology and infectious disease, 64(1), 83-84.

12. Muller, D. A., \& Young, P. R. (2013). The flavivirus NS1 protein: molecular and structural biology, immunology, role in pathogenesis and application as a diagnostic biomarker. Antiviral research, 98(2), 192-208.

13. Hang, V. T., Nguyet, N. M., Tricou, V., Yoksan, S., Dung, N. M., Van Ngoc, T., ... \& Simmons, C. P. (2009). Diagnostic accuracy of NS1 ELISA and lateral flow rapid tests for dengue sensitivity, specificity and relationship to viraemia and antibody responses. PLoS neglected tropical diseases, 3(1), e360.

14. Andries, A. C., Duong, V., Ngan, C., Ong, S., Huy, R., Sroin, K. K., ... \& Buchy, P. (2012). Field evaluation and impact on clinical management of a rapid diagnostic kit that detects dengue NS1, IgM and IgG. PLoS neglected tropical diseases, 6(12), e1993.

15. Bessoff, K., Delorey, M., Sun, W., \& Hunsperger, E. (2008). Comparison of two commercially available dengue virus (DENV) NS1 capture enzyme-linked immunosorbent assays using a single clinical sample for diagnosis of acute DENV infection. Clin. Vaccine Immunol., 15(10), 15131518.

16. Colombo, T. E., Vedovello, D., Araki, C. S., CogoMoreira, H., dos Santos, I. N. P., Reis, A. F. N., ... \& Junior, J. F. (2013). Dengue-4 false negative results by Panbio® Dengue Early ELISA assay in Brazil. Journal of Clinical Virology, 58(4), 710712.

17. Ramirez, A. H., Moros, Z., Comach, G., Zambrano, J., Bravo, L., Pinto, B., ... \& Liprandi, F. (2009). Evaluation of dengue NS1 antigen detection tests with acute sera from patients infected with dengue virus in Venezuela. Diagnostic microbiology and infectious disease, 65(3), 247-253.

18. Halstead, S. B. (2007). Dengue. The lancet, 370(9599), 1644-1652.

19. Chanama, S., Anantapreecha, S., Atchareeya, A., Sa-gnasang, A., Kurane, I., \& Sawanpanyalert, P. (2004). Analysis of specific IgM responses in secondary dengue virus infections: levels and positive rates in comparison with primary infections. Journal of Clinical Virology,31(3), 185-189.

20. Matheus, S., Pham, T. B., Labeau, B., Huong, V. T. Q., Lacoste, V., Deparis, X., \& Marechal, V. (2014). Kinetics of dengue non-structural protein 1 antigen and $\operatorname{IgM}$ and $\operatorname{IgA}$ antibodies in capillary blood samples from confirmed dengue patients. The American journal of tropical medicine and hygiene, 90(3), 438-443.

21. Hunsperger, E. A., Yoksan, S., Buchy, P., Nguyen, V. C., Sekaran, S. D., Enria, D. A., ... \& Gubler, D. J. (2009). Evaluation of commercially available anti-dengue virus immunoglobulin $\mathrm{M}$ tests. Emerging infectious diseases, 15(3), 436.

22. Lanciotti, R. S., Calisher, C. H., Gubler, D. J., Chang, G. J., \& Vorndam, A. V. (1992). Rapid detection and typing of dengue viruses from clinical samples by using reverse transcriptasepolymerase chain reaction. Journal of clinical microbiology, 30(3), 545-551.

23. Deubel, V., Laille, M., Hugnot, J. P., Chungue, E., Guesdon, J. L., Drouet, M. T., ... \& Chevrier, D. (1990). Identification of dengue sequences by genomic amplification: rapid diagnosis of dengue virus serotypes in peripheral blood. Journal of virological methods, 30(1), 41-54.

24. Waggoner, J. J., Abeynayake, J., Sahoo, M. K., Gresh, L., Tellez, Y., Gonzalez, K., ... \& Sambri, V. (2013). Single-reaction, multiplex, real-time rtPCR for the detection, quantitation, and serotyping of dengue viruses. PLoS neglected tropical diseases, 7(4), e2116. 
25. Johnson, B. W., Russell, B. J., \& Lanciotti, R. S. (2005). Serotype-specific detection of dengue viruses in a fourplex real-time reverse transcriptase PCR assay. Journal of clinical microbiology, 43(10), 4977-4983.

26. Waggoner, J. J., Abeynayake, J., Sahoo, M. K., Gresh, L., Tellez, Y., Gonzalez, K., ... \& Pinsky, B. A. (2013). Development of an internally controlled real-time reverse transcriptase PCR assay for pandengue virus detection and comparison of four molecular dengue virus detection assays. Journal of clinical microbiology, 51(7), 2172-2181.

27. Ito, M., Takasaki, T., Yamada, K. I., Nerome, R., Tajima, S., \& Kurane, I. (2004). Development and evaluation of fluorogenic TaqMan reverse transcriptase PCR assays for detection of dengue virus types 1 to 4. Journal of clinical microbiology, 42(12), 5935-5937.

28. Ibrahim, F., Taib, M. N., Sulaiman, S., \& Abas, W. W. (2001, December). Dengue fever (DF) and dengue haemorrhagic fever (DHF) symptoms analysis from an expert system perspective. In Proceedings. IEEE International Multi Topic Conference, 2001. IEEE INMIC 2001. Technology for the 21st Century. (pp. 212-215). IEEE.

29. Bhatnagar, J., Guarner, J., Paddock, C. D., Shieh, W. J., Lanciotti, R. S., Marfin, A. A., ... \& Zaki, S. R. (2007). Detection of West Nile virus in formalin-fixed, paraffin-embedded human tissues by RT-PCR: a useful adjunct to conventional tissue-based diagnostic methods. Journal of clinical virology, 38(2), 106-111.

30. Laue, T., Emmerich, P., \& Schmitz, H. (1999). Detection of dengue virus RNA in patients after primary or secondary dengue infection by using the TaqMan automated amplification system. Journal of clinical microbiology, 37(8), 2543-2547.

31. Singh, K., Lale, A., Ooi, E. E., Chiu, L. L., Chow, V. T., Tambyah, P., \& Koay, E. S. (2006). A prospective clinical study on the use of reverse transcription-polymerase chain reaction for the early diagnosis of dengue fever. The Journal of Molecular Diagnostics, 8(5), 613-616.

32. Tricou, V., Minh, N. N., Farrar, J., Tran, H. T., \& Simmons, C. P. (2011). Kinetics of viremia and NS1 antigenemia are shaped by immune status and virus serotype in adults with dengue. PLoS neglected tropical diseases, 5(9), e1309.

33. Palomares-Reyes, C., Silva-Caso, W., del Valle, L. J., Aguilar-Luis, M. A., Weilg, C., Martins-Luna, J., \& Espíritu, W. E. (2019). Dengue diagnosis in an endemic area of Peru: Clinical characteristics and positive frequencies by RT-PCR and serology for NS1, IgM, and IgG. International Journal of Infectious Diseases, 81, 31-37.

34. Guzman, J. C., \& Martin, J. A. (2018). Analyzing the effectiveness and limitations of clinical diagnostic techniques for dengue fever in rural Philippines. International Journal of Infectious Diseases, 73, 273. 